2009

pp. 133-155

\title{
Real Options and Escalation of Commitment: A Behavioral Analysis of Capital Investment Decisions
}

\author{
Christine A. Denison \\ Iowa State University
}

\begin{abstract}
This study uses experimental methods to explore whether incorporating real options into net present value analysis can reduce escalation of commitment, or the tendency of decision makers to continue to commit resources to a project after receiving negative feedback. This reduction in escalation behavior should occur because the incorporation of real options offers the user greater cognitive accessibility to the possibility of project abandonment. Findings indicate that users of real options exhibit less escalation of commitment than do users of net present value analysis alone. The main result demonstrates that the use of real options in capital budgeting can affect the behavior and decisions of the user even in an experimental setting that controls for the informational advantage of using real options.
\end{abstract}

Keywords: real options; escalation of commitment; capital budgeting; sunk cost effect.

Data Availability: Available from the author upon request.

\section{INTRODUCTION}

7 his study examines whether decision makers who use real options in capital budgeting are less likely to escalate commitment to a failing course of action than decision makers who use discounted cash flow techniques such as net present value alone. Escalation of commitment occurs when decision makers continue to commit resources to a project after receiving negative feedback about the effects of prior resource commitments (see Staw [1997] for a review). The finding that decision makers escalate commitment to failing courses of action is robust across many settings and conditions, including capital investment situations.

In prior research on the escalation of commitment phenomenon, participants have not been allowed or required to calculate the value of capital budgeting projects using such

I gratefully acknowledge the helpful comments and suggestions of Sue Ravenscroft, Cristi Gleason, Diane Janvrin, Bruce Johnson, and Kristy Towry, two anonymous reviewers, workshop participants at the University of Iowa and Iowa State University, the University of Iowa Judgment and Decision-Making group, and the AAA annual meeting, as well as my dissertation committee: Ramji Balakrishnan, Russell Lenth, Irwin Levin, Dhananajay Nayakankuppam, Ashish Tiwari, and especially my chair, Richard Tubbs, whose assistance and guidance has been immeasurable. Thanks also to Jeff Burks, Mike Maier, and Ron Guymon for assistance with the experiment.

Editor's note: Accepted by Steven Kachelmeier, with thanks to Marlys Lipe for serving as editor on a previous version. 
techniques as net present value or internal rate of return, even though the application of such techniques is common in the business world (Graham and Harvey 2001). Of particular interest in this study is the incorporation of real options into capital budgeting techniques. Real options analysis takes the techniques developed to value financial options and applies them to the valuation of other endeavors in which uncertainty is a factor, such as business ventures, product lines, or entire firms. Using real options in capital budgeting involves explicitly considering the value of managerial flexibility over the time a project unfolds. For example, such flexibility exists when management has the right to terminate a project early, expand a project after an initial toehold investment, or extend a product line to better utilize technology investments. Incorporating real options into the capital budgeting process allows decision makers to add the value of management's options to the discounted cash flow value of a project.

Proponents of the real options approach to capital budgeting claim that it results in decisions superior to those made using discounted cash flow techniques alone (Teach 2003; Copeland and Antikarov 2001; Coy 1999; Ross 1995). These arguments are based on the fact that including the value of real options increases the quality of information available to managers. This informational advantage is not tested in this study, as it has been addressed by copious amounts of research (e.g., Newton et al. 2004; Teach 2003; Copeland and Antikarov 2001). However, the use of different techniques can have effects on a decision maker's behavior other than those produced by a difference in information quality. For example, different techniques could highlight the importance of different aspects of the project, leading the manager to focus more on those particular aspects, and ultimately leading the manager to a different decision than might have been made had another technique been used to evaluate the project. There has been very little research on how the use of real options in capital budgeting affects the behavior and decisions of managers in this way. This study explores such behavioral effects by examining whether the use of real options in capital budgeting can affect escalation of commitment.

Whether the use of real options in capital budgeting can reduce the tendency of decision makers to escalate commitment to a failing project is an open question. This study theorizes that because real options techniques involve considering and valuing the option to abandon a project, that option should be more cognitively accessible to decision makers and thus more likely to be exercised. Other research has argued that real options can help overcome "antifailure bias" (McGrath 1999), which suggests that managers who use real options analysis may be less likely to escalate commitment to failing projects. However, some critics of real options in both the academic and popular press have theorized that because there is no specific exercise date or expiration date on an abandonment option, managers may delay abandoning projects past the time when they should be abandoned. They argue that such delays would exacerbate the escalation of commitment problem rather than reducing it (Adner and Levinthal 2004; Zardhooki 2004; Teach 2003; Fink 2001). Thus, it is not entirely clear from theory or past research what effect the use of real options in capital budgeting will have on escalation of commitment to a failing project, and no empirical research to date has directly addressed the question. This study provides evidence to inform the debate.

The question addressed by the current study is important for a number of reasons. The study contributes to the escalation of commitment literature by exploring the boundaries to which escalation generalizes, and by providing a new avenue for mitigating the phenomenon. It contributes to the real options literature by providing theory and empirical evidence to inform the debate as to whether the explicit consideration of real options in capital budgeting affects escalation of commitment. More generally, it provides evidence as to how 
the use of real options in capital budgeting affects managers' behavior and decisions by demonstrating differences across capital budgeting methods even in an experimental setting that controls for the informational advantage of using real options. The paper also contributes to the management accounting literature by exploring in more depth a judgment bias associated with capital budgeting, namely escalation of commitment, and examining whether the use of real options affects the occurrence of this bias. Finally, it may contribute to practice by offering managers a way to improve firm performance by reducing escalation of commitment.

To address the research question, an experiment was conducted in which participants used either a discounted cash flow method alone or a discounted cash flow method incorporating real options to evaluate a project, and participants' recommendations to continue the project were measured. In the experiment, the participants should make the same decision regardless of capital budgeting method. Any difference in behavior between those using real options and those using discounted cash flow techniques alone, therefore, would be due to psychological or behavioral effects of the techniques. The experiment also addressed the proposed psychological mechanism underlying the effect, as did a second experiment, which corrected for measurement error issues in the first experiment.

The study finds that participants who explicitly consider real options exhibit less escalation of commitment than do users of net present value analysis alone. This reduction in escalation of commitment occurs despite the fact that there is no significant difference in initial commitment to the project between the two groups, both groups were aware of the abandonment option, and both methods should lead to the same conclusion regarding abandonment. The results suggests that the use of real options analysis can have beneficial behavioral effects in addition to yielding information superior to that produced using the net present value method alone.

The remainder of the paper is organized as follows. Section II reviews the extant literature relating to escalation of commitment and real options. Section III describes the hypotheses and related theory. Section IV describes the first experiment. Section V discusses additional evidence on $\mathrm{H} 2$, including the results of a second experiment. Section VI discusses the results, implications, and limitations of the study.

\section{Escalation of Commitment}

\section{LITERATURE REVIEW}

Escalation of commitment to a failing course of action, or simply "escalation of commitment" or "escalation," refers to a situation in which a decision maker is faced with negative feedback about a prior decision, but continues to commit resources to the choice despite this negative feedback (see Staw [1997] for a review). This phenomenon has been studied in many contexts since its introduction to the literature over 30 years ago (Staw 1976), including sports (Staw and Hoang 1995), information technology (Drummond 1996; Keil et al. 1994), and management (Miller et al. 1997). Accounting researchers have tended to focus on escalation of commitment in a capital investment setting (Schulz and Cheng 2002; Rutledge and Karim 1999; Chow et al. 1997; Harrell and Harrison 1994; Kanodia et al. 1989), and also on factors that mitigate escalation tendencies (Kadous and Sedor 2004; Cheng et al. 2003; Ghosh 1997; Jeffrey 1992; Beeler 1988).

No escalation of commitment studies in a capital investment setting to date have required participants to apply capital budgeting techniques, so it is unclear whether such techniques can reduce escalation of commitment. However, prior research is informative as to some of the components of the capital budgeting process, including using a quantitative strategy rather than making an intuitive judgment, preparing a report, and using hurdle 
rates. Conlon and Wolf (1980) address whether using a "calculating strategy" can reduce escalation of commitment. They find that using such a strategy interacts with other factors, but does not have a main effect on escalation. Ghosh (1997) finds that preparing a progress report on the project at the time of the setback can reduce escalation of commitment; however, this study does not address preparing a report during the initial phase of capital budgeting. Studies have also found that the use of organization-set hurdle rates is ineffective in reducing escalation of commitment (Cheng et al. 2003; Schmidt and Calantone 2002). As a whole, these studies do not make clear what effect the use of capital budgeting techniques will have on escalation of commitment.

\section{Real Options}

The term "real options" was coined 30 years ago to refer to the use of options valuation techniques in real investment scenarios (Myers 1977). Myers (1977) introduces real options as a way of using financial options theory to value firms, and predicts corporate borrowing patterns as a function of the proportion of firm value accounted for by real options. Since then, numerous researchers in finance and management have studied the use of real options, not only for firm valuation, but also as a supplement to discounted cash flow techniques in capital budgeting (see Lander and Pinches [1998], Trigeorgis [1997], and Dixit and Pindyck [1994] for an overview of this literature). In addition to scholarly research on the subject, a number of consulting firms have been formed and books published to help firms implement real options in practice (e.g., Copeland and Antikarov 2001; Howell et al. 2001; Amram and Kulatilaka 1999).

The use of real options in capital budgeting basically involves considering possible decision points that could arise as a project unfolds and the best response of management at each of these decision points. The value of the project should management choose the best option at each of these points is calculated, and a weighted average of these possible outcomes is taken based on their probability of occurrence. The resulting project value will always be greater than or equal to the net present value of the project without considering real options, since net present value is basically an expected value of all possible outcomes while considering real options involves averaging only those outcomes that would occur should management choose the best course of action at each decision point. The difference between project value considering real options and the net present value of the project reflects the value of flexibility available to management.

One paper to date has examined the connection between real options and escalation of commitment using experimental methodology, although a number of differences set that study apart from the present one. Tiwana et al. (2006) experimentally tests the suggestion of Keil and Flatto (1999) that the presence of real options in a project can sometimes make escalation of commitment a rational phenomenon. The two studies posit that continuing commitment to a project that has suffered a setback may occur because the real options associated with the project make its future value positive, but that value is not apparent because those real options were not considered in placing an initial value on the project. Their scenario is different from that in the current study, which considers a situation in which the future value of the project after a setback is negative, and the value of real options associated with the project is explicitly considered in the valuation stage.

Very few papers have examined the behavioral implications of real options, although a number of real options researchers have called for such an examination (McGrath 1999; Kogut and Kulatilaka 1994; Bowman and Hurry 1993). Those studies that exist in this area (Tiwana et al. 2007; Yavas and Sirmans 2005; Miller and Shapira 2004; Howell and Jagle 1997; Busby and Pitts 1997) are largely concerned with how decision makers perceive the 
real option value associated with projects in situations where the value of such options has not been explicitly incorporated into the initial project evaluation. Very little has been done to examine whether the use of real options in capital budgeting can lead to superior decisions.

\section{HYPOTHESIS DEVELOPMENT}

Psychology research has long demonstrated that more accessible cognitive constructs are more likely to influence thoughts and behaviors (Fazio and Towles-Schwen 1999; Fazio and Williams 1986). The accessibility of a cognitive construct is defined as the ease with which it can be brought to mind (Etcheverry and Le 2005; Higgins 1996; Fazio et al. 1986). The accessibility of such constructs as personality traits, goals, attitudes, and choice options has considerable influence on subsequent cognitions, behaviors, and choices (Bargh and Thein 1985; Chartrand and Bargh 1996; Fazio and Towles-Schwen 1999; Posavac et al. 1997). Construct accessibility is often increased through rehearsal, or frequent activation of the construct that occurs over time (Etcheverry and Le 2005; Fazio and Williams 1986; Fazio et al. 1986).

Surveys indicate that in capital budgeting situations, the most commonly used analysis tools are net present value and other discounted cash flow techniques (Graham and Harvey 2001). However, the net present value technique considers only the expected value of a project's future cash flows, and does not explicitly consider the option of abandoning a project before completion. Decision makers who incorporate real options into the analysis, on the other hand, explicitly take into account the flexibility management may have in choosing to abandon a project early or see it through to the end, and calculate a specific value attached to this early abandonment option. Managers who use real options in their capital budgeting decisions as a matter of course, therefore, will be repeatedly exposed to the construct of early project abandonment, while managers who use net present value analysis alone will not. This exposure should heighten the accessibility of the possibility of early abandonment for users of real options valuation analysis relative to users of net present value analysis alone.

Construct accessibility can have a great effect on how decision makers perceive and use the information they receive, and on their subsequent choices and behaviors (Bargh and Ferguson 2000; Ratneshwar et al. 1997; Higgins et al. 1982; Posavac et al. 1997). Psychology studies have found that "differences in construct accessibility led to temporary processing differences, which, in turn, can have long-term behavioral and cognitive consequences" (Higgins et al. 1982). Recently, Posavac et al. (1997) examined how the accessibility of choice options affected the choices selected by research participants. They found that when decision alternatives were clearly specified, decision makers made choices that were consistent with their attitudes. However, when decision alternatives were not specified, decision maker' attitudes played a role in making their choices only if those choice options were cognitively accessible. Capital budgeting projects are scenarios in which choice options are not always specified, and indeed when it is not always apparent that a decision needs to be made at all (Bragger et al. 1998). As suggested by Posavac et al. (1997), in such a situation, the construct accessibility of a choice option such as early abandonment of the project could be crucial in whether the manager eventually takes that option.

Indeed, the construct accessibility of the possibility of abandonment can affect how evidence of impending project failure is perceived and interpreted in the first place. When a cognitive construct is highly accessible, it is more likely to become activated automatically when a relevant stimulus, such as evidence that a project is failing, is encountered (Fazio 
and Williams 1986). "Ceteris paribus, the more accessible or salient a concept, the more likely it will be used in the perception of new information" (Ratneshwar et al. 1997). This suggests that decision makers to whom the possibility of project abandonment is more accessible would be more likely to consider, and act on, the idea of abandoning a project earlier if they encounter signs of project failure. Thus, the tendency to escalate commitment to a failing project should be lower for those to whom the concept of early abandonment is more accessible. This leads to the following research hypotheses:

H1: Decision makers will be less likely to escalate commitment to a failing project when real options are explicitly considered in the planning phase of a capital budgeting project than when discounted cash flow techniques alone are used.

H2: The cognitive accessibility of the possibility of project abandonment mediates the relationship between the capital budgeting technique a decision maker uses and that decision maker's escalation of commitment to a failing project.

\section{EXPERIMENT 1}

To test the hypotheses, a $2 \times 2$ between-subjects experiment was conducted in which the capital budgeting method used by participants and the order in which participants performed tasks were varied. Recommendations to continue the project and construct accessibility of the possibility of abandonment were measured. The method, analysis, and results of Experiment 1 are described below.

\section{Participants}

Forty-five Master of Business Administration and Master of Accounting students participated in the experiment. On average, these students were 26.33 years old, had 3.1 years of work experience, and 48.8 percent were female. This population was chosen because of the familiarity of the participants with capital budgeting scenarios and the similarity of the participants to the population of interest, actual business managers.

\section{Procedure}

Participants were randomly assigned to one of two conditions in which they played the role of a controller at an electronics firm that used either net present value analysis alone or incorporated real options into the analysis, depending on condition. They were told that their responsibilities included performing financial analysis for capital budgeting projects and making recommendations as to whether such projects should be undertaken or continued. They were also told what capital budgeting technique was used by their firm, including instructions on how to perform an analysis using that technique. They were given an example problem using the firm's capital budgeting technique, and told that they could refer back to the example at any time when performing their own calculations. Participants were then given information about a project, namely the development of an all-in-one cell phone, organizer, and MP3 player. They were given information about the cash flows of the project, its life, and its probability of success (see the Appendix for this information). Participants were then asked to calculate the value of the project using the firm's capital budgeting technique, and to indicate the likelihood that they would recommend funding the project on a 101-point scale ranging from 0 (not at all likely) to 100 (extremely likely). Participants were also asked to defend their choice with a short justification statement.

The information given should lead to an unambiguous choice to undertake the project, as the net present value of the project is $\$ 30,960,000$ and the value of the project including 
real options is $\$ 39,864,000$ (see the Appendix for calculations). Since both these values are positive, participants should unanimously decide to fund the development of the device. Any answers below 50 (undecided) indicate a lack of understanding of capital budgeting techniques, or an error in performing the capital budgeting analysis (four participants [9.76 percent] chose a response below 50; their data as well as that of one participant who failed to respond to the question are excluded from all analyses). The purpose of the decision at this stage is twofold: to determine whether incorporating real options into the analysis results in different project acceptance rates, and to establish the personal responsibility of the participants for the project at hand, which is an important, although not strictly necessary, antecedent condition for escalation of commitment to occur (Schoorman and Holahan 1996; Goltz 1993).

After making the initial project recommendation, half the participants were asked to imagine situations in which they would be called on to perform analysis and make project recommendations once the project is underway. Participants were asked to list these situations, as well as their recommendations for these situations, in the space provided. All participants were then given a memo from the president of the company informing them that the all-in-one project had experienced a major setback; namely, that a competitor had developed a superior product. The memo contained information about sunk costs already incurred in the project, the degree of project completion, and the potential impact on demand. At this point, uncertainty in the project is resolved, which would make the project value and procedure used identical whether net present value analysis is used alone or real options are considered. A correct analysis of the information would yield a net present value of continuing the project as $\$ 22,740,000$ and abandonment value of $\$ 49,500,000$ (see the Appendix for calculations), regardless of whether real options are considered, so the economically correct choice would be to abandon the project. Given this information, participants made a recommendation as to whether to continue the project or abandon it by indicating on a $0-100$ scale the likelihood that they would recommend continuation, and defended their answer with a short justification statement. After performing this task, the participants who did not previously perform the thought-listing task did so.' Finally, participants answered demographic and manipulation check questions.

\section{Design}

Experiment 1 is a $2 \times 2$ split-plot design, in which capital budgeting method (CapBud) is manipulated as a between-subjects variable and timing of recommendation (Time) is manipulated as a within-subjects variable. The first independent variable, CapBud, is manipulated at two levels. Participants were randomly assigned to one of these two conditions. In one condition, participants were told that the firm uses net present value in initial project evaluations, and were asked to calculate the net present value of the project. In the second condition, participants were told that the firm explicitly considers real options in the planning phase of its projects, and were asked to calculate the net present value of the project including the value of real options. The second independent variable, Time, captures the fact that participants made recommendations as to whether to continue the project at two points in time (Time 1 is their initial recommendation and Time 2 is their recommendation to continue after the occurrence of the setback).

\footnotetext{
1 The order in which participants completed the thought-listing task and the project recommendation task was varied to determine whether differences in order affected the results. Participants were randomly assigned to one of two order conditions. The interaction between order and the independent variable was not significant, so the data were collapsed across order conditions in subsequent analyses.
} 
The dependent variable of interest in testing $\mathrm{H} 1$ is the participants' recommendation to continue the project (RCP). RCP is measured by participants' recommendation to undertake or continue the project on a 101-point scale ranging from 0 (not at all likely) to 100 (extremely likely). At Time 2, higher RCP scores indicate a greater degree of escalation of commitment. Escalation of commitment is often measured as the amount of money decision makers would commit to the decision, but in this case the decision maker is making a recommendation rather than a monetary commitment. Thus, escalation of commitment is measured on a scale indicating likelihood of recommending project continuation, similar to Kadous and Sedor (2004).

The dependent variable of interest in testing $\mathrm{H} 2$ is a measure of the construct accessibility of the possibility of abandoning the project early (CAPA). CAPA is captured using three different measures: (1) whether the participant recommended abandoning the project in any of the situations, (2) the percentage of situations in which the participant's recommendation is to abandon the project, and (3) the rank order in which the participant first lists a situation in which the recommendation is to abandon the project (scaled by number of recommendations). A factor analysis is run on the three measures of CAPA in which one factor was extracted, which explained 92.9 percent of the variance. ${ }^{2}$ The factor score for each participant with respect to this factor is the CAPA measure used in the data analysis. ${ }^{3}$

\section{Results}

\section{Manipulation Checks}

Participants were asked both to what extent they agreed that the firm used net present value and to what extend they agreed that the firm used real options to evaluate its investment decisions on a scale of -5 to 5 . The mean responses were significantly different across conditions on both questions $(p<0.001$ ), in both cases in the direction indicating that subjects understood the capital budgeting method used by the firm.

Other manipulation check questions asked whether participants agreed that making the right decision was important (at both Time 1 and Time 2), the case was easy to understand, the case was difficult to do, and the case was very realistic. There were no significant differences between the means for the net present value and real options conditions on the importance questions $(p=0.566,0.309)$, the difficulty question $(p=0.071)$ or the realism question ( $p=0.316$ ). However, net present value participants found the case easier to understand $(\mathrm{p}=0.002)$, but both groups had significantly positive means $(\mathrm{p}<0.001$ for both) indicating that participants in both groups found the case easy to understand. ${ }^{4}$

\section{Test of Hypothesis 1}

To test H1, an ANOVA was conducted in which RCP was the dependent measure, CapBud was a between-subjects effect and Time and CapBud $\times$ Time were within-subjects effects. Panel A of Table 1 presents the results of this ANOVA, and Panel B of Table 1

2 The correlation (p-value) between CAPA1 and CAPA2 was 0.848 ( $\mathrm{p}<0.001$ ), between CAPA1 and CAPA3 $0.898(\mathrm{p}<0.001)$, and between CAPA2 and CAPA3 $0.934(\mathrm{p}<0.001)$. The factor analysis yielded loadings on the extracted factor (correlation coefficients between each variable and the extracted factor) of 0.949 for CAPA1, 0.962 for CAPA2, and 0.980 for CAPA3.

3 Factor scores are calculated as the sum of the standardized scores for each variable multiplied by the standardized scoring coefficient for that variable. Standardized scoring coefficients are 0.341 for CAPA1, 0.345 for CAPA2, and 0.352 for CAPA3.

4 A supplemental analysis including this question as a covariate yielded similar results to those discussed in the main analysis. 


\section{TABLE 1 \\ Experiment 1 \\ Experimental Results: Recommendation to Continue Project (RCP)}

Panel A: ANOVA on RCPa

\begin{tabular}{|c|c|c|c|c|c|}
\hline Source of Variation & $\underline{\mathrm{df}}$ & SS & MS & $\mathbf{F}$ & $\mathbf{p}$ \\
\hline \multicolumn{6}{|l|}{ Between Subjects } \\
\hline CapBud & 1 & 4103.63 & 4103.63 & 7.20 & 0.01 \\
\hline Subjects (CapBud) & 38 & 21654.30 & 569.85 & & \\
\hline \multicolumn{6}{|l|}{ Within Subjects } \\
\hline Time & 1 & 28325.34 & 28325.34 & 46.29 & $<0.01$ \\
\hline CapBud*Time & 1 & 4554.24 & 4554.24 & 7.44 & $<0.01$ \\
\hline Residual & 38 & 23251.90 & 611.89 & & \\
\hline
\end{tabular}

Panel B: Least-Squares Means: RCP

\begin{tabular}{lc|c|} 
& \multicolumn{2}{c}{$\begin{array}{c}\text { Capital Budgeting } \\
\text { Method }\end{array}$} \\
\cline { 2 - 3 } Time & $\begin{array}{c}\text { NPV } \\
\mathbf{n}=\mathbf{2 1}\end{array}$ & $\begin{array}{c}\text { Real Options } \\
\mathbf{n}=\mathbf{1 9}\end{array}$ \\
\cline { 2 - 3 } Time 1 & 81.79 & 82.55 \\
\cline { 2 - 3 } Time 2 & 59.21 & 29.76 \\
\cline { 2 - 3 } & 70.50 & 56.16
\end{tabular}

\footnotetext{
"Likelihood of recommending project continuation measured on a 101-point scale with 0 labeled "Not at all likely," 50 labeled "Undecided," and 100 labeled "Extremely likely." The appropriate error term for CapBud is the Subjects(CapBud) mean square. The appropriate error term for Time and CapBud*Time is the residual mean square.
}

presents the least-squares mean RCP. Panel A indicates that all effects in the model are highly significant.

The first result emerging from this analysis is the difference between the least-squares means for the two capital budgeting techniques at Time $1 .^{5}$ Panel $\mathrm{B}$ of Table 1 indicates that the mean RCP for the net present value condition at Time 1 was 81.79 , while the mean $\mathrm{RCP}$ for the real options condition at Time 1 was 82.55 . The difference between these is not statistically significant $(t=0.100$, one-tailed $\mathrm{p}=0.461) .^{6}$ Thus, there is no significant difference between participants in the two conditions as to whether they initially recommended undertaking the project.

The effect of interest in testing $\mathrm{H} 1$ is the difference between the least-squares means for the two capital budgeting techniques at Time 2. Panel B of Table 1 indicates that the mean RCP for the net present value condition at Time 2 was 59.21 , while the mean RCP for the real options condition at Time 2 was 29.76. The difference between these is statistically significant $(\mathrm{t}=3.827$, one-tailed $\mathrm{p}<0.001)$. This is consistent with $\mathrm{H} 1$, which predicts that the real options mean will be less than the net present value mean. Participants

\footnotetext{
5 Data for participants whose response was below 50 were excluded, as this indicated that they did not properly apply capital budgeting techniques. Including this data does not change the conclusions reached. The least-squares means for each condition when these responses are left in are 78.16 for the net present value condition and 75.48 for the real options condition; these are not significantly different $(F=0.17, p=0.68)$.

${ }^{6}$ The appropriate error term for this contrast, as well as all subsequent planned contrasts, is a linear combination of the Subjects(CapBud) mean square and the residual mean square.
} 
in the real options condition displayed significantly lower escalation of commitment than participants in the net present value condition. This effect occurs despite the fact that the two groups did not make significantly different recommendations at Time 1, immediately after the manipulation occurred. ${ }^{7}$ There is no significant correlation between recommendations at Time 1 and recommendations at Time 2 (Pearson correlation $=-0.06, p=0.71$ ).

An alternative way to test $\mathrm{H} 1$ is to analyze the data based on the percentage of participants who recommended continuing the project in each condition, which can be done if an RCP score of 50 is considered the threshold between recommending continuation versus abandonment of the project. ${ }^{8}$ Each RCP score above 50 would indicate a participant who displayed escalation of commitment to the project. Table 2 presents the number and percentage of participants in each condition with RCP scores above 50. An examination of Table 2 reveals that at Time $2,66.67$ percent of participants in the net present value condition displayed escalation of commitment, while only 21.05 percent of participants in the real options condition displayed escalation of commitment. A Chi-square test using the number of participants displaying escalation of commitment at Time 2 indicates that net present value users are more likely to escalate commitment than real options analysis users $\left(\chi^{2}=8.39, \mathrm{p}=0.004\right)$. This is consistent with $\mathrm{H} 1$.

\section{Test of Hypothesis 2}

A path analysis was performed to test the proposed mechanism by which the capital budgeting technique affects escalation of commitment, namely through the construct accessibility of the possibility of abandonment. This path analysis indicates both the direct effect of CapBud on RCP and the indirect effect of CapBud on RCP through CAPA at Time 2. Results of the path analysis are presented in Figure 1. The path coefficient for the direct effect, -0.3692 , is statistically significant (two-tailed $p=0.021$ ) and in the expected direction, indicating that participants in the real options condition (coded 1) are less likely to recommend continuing the project than participants in the net present value condition

\section{TABLE 2}

Experiment 1

Experimental Results: Number and Percentage of Participants Recommending Continuation ${ }^{\mathrm{a}}$

\begin{tabular}{|c|c|c|c|}
\hline \multirow[b]{2}{*}{ Time } & \multicolumn{2}{|c|}{ Capital Budgeting Method } & \multirow{4}{*}{$\begin{array}{c}\mathrm{n}=40 \\
100.00 \% \\
\mathrm{n}=18 \\
45.00 \%\end{array}$} \\
\hline & $\begin{array}{c}\text { NPV } \\
n=21\end{array}$ & $\begin{array}{c}\text { Real Options } \\
n=19\end{array}$ & \\
\hline$\overline{\text { Time } 1}$ & $\begin{array}{c}\mathrm{n}=21 \\
100.00 \%\end{array}$ & $\begin{array}{c}\mathrm{n}=19 \\
100.00 \%\end{array}$ & \\
\hline \multirow[t]{2}{*}{ Time 2} & $\begin{array}{l}\mathrm{n}=14 \\
66.67 \%\end{array}$ & $\begin{array}{c}\mathrm{n}=4 \\
21.05 \%\end{array}$ & \\
\hline & $\begin{array}{l}\mathrm{n}=35 \\
83.33 \%\end{array}$ & $\begin{array}{l}\mathrm{n}=23 \\
60.52 \%\end{array}$ & \\
\hline
\end{tabular}

a Proportion of participants recommending continuation is calculated as the number of participants in each cell whose RCP was greater than 50 as a percentage of total participants in the cell.

7 Not all participants performed a mathematically correct analysis at Time 1 . Repeating the main analysis using only the data from participants who performed a correct analysis does not change the conclusions reached in the main analysis.

8 An examination of the justification statements written by participants at Time 2 indicates that they viewed RCP scores above 50 as recommending continuation, and RCP scores below 50 as recommending abandonment. 
FIGURE 1

Experiment 1

Path Analysis

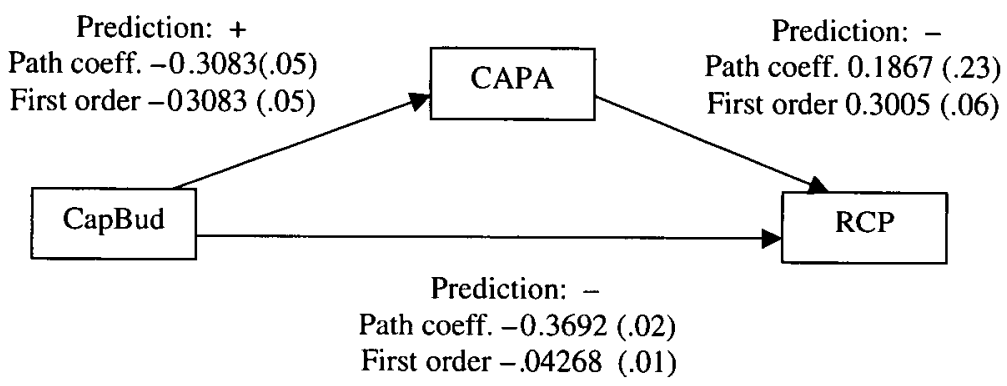

Path analytic model of CapBud (capital budgeting method), CAPA (construct accessibility of the possibility of abandoning the project early), and RCP (recommendation to continue the project). Path (standardized regression) coefficients are reported on paths with p-values in parentheses. First order correlations are also reported on paths with p-values in parentheses. CapBud is manipulated as either net present value (coded 0) or real options (coded 1) analysis. CAPA is measured as the factor score from a factor analysis of the occurrence, frequency, and rank order of recommendations to abandon the project early in an open-response thought-listing task in which one factor was extracted. RCP is measured as the likelihood of recommending project continuation at Time 2 measured on a 101-point scale with 0 labeled "Not at all likely," 50 labeled "Undecided," and 100 labeled "Extremely likely."

(coded 0). However, the indirect effect of CapBud on RCP through CAPA, which can be obtained by multiplying together the two coefficients on that path, is only -0.0576 , which is not statistically significant (Sobel test statistic $=1.09$, two-tailed $p=0.276$ ). This is inconsistent with $\mathrm{H} 2$.

In addition, the path coefficients linking CapBud to CAPA and CAPA to RCP are puzzling. According to theory, users of real options should display greater construct accessibility of the possibility of abandonment, but the path coefficient from CapBud to CAPA is significantly negative $(-0.3083$, two-tailed $p=0.053)$, indicating that using real options actually decreases CAPA. Furthermore, higher CAPA should result in lower RCP, but the path coefficient from CAPA to RCP is positive and not statistically significant $(0.1867$, twotailed $p=0.231$ ). These results are also inconsistent with $\mathrm{H} 2$.

The fact that the results regarding CAPA are in the opposite direction from that predicted indicates that either the effect of the use of real options is working through an alternate, unspecified mechanism, or the measure of the theoretical construct is inadequate. Construct accessibility is a difficult concept to capture, since measuring it directly would increase the accessibility of the construct at hand, thus affecting the participant's response to the measure and performance on subsequent measures. Because an indirect measure must be used, it is possible that the construct was not adequately captured. This possibility will be discussed fully in Section V.

\section{Additional Analysis: Work at Time 2}

An examination of work done by participants at Time 2 indicates that some participants performed a new discounted cash flow analysis at that point, while others did not. To investigate the effect of this recalculation on their Time 2 recommendations, a new variable, T2Calc, was coded as 0 if the participant did not perform new calculations at Time 2 and 1 if the participant did perform new calculations at Time 2. An ANOVA was conducted in 
which RCP at Time 2 was the dependent measure and CapBud and T2Calc were independent measures. The results of this ANOVA are reported in Table 3, along with cell means and cell sizes. These results indicate that while the main effect of capital budgeting technique on RCP at Time 2 is significant $(F=6.06, p=0.019)$, as expected, so is the main effect of T2Calc on RCP at Time $2(F=9.20, p=0.005)$. The interaction was not significant $(\mathrm{F}=0.97, \mathrm{p}=0.331)$. Participants using either capital budgeting method were more likely to abandon the project at Time 2 if they performed new calculations at that point.

\section{ADDITIONAL EVIDENCE ON HYPOTHESIS 2}

\section{Evidence of Measurement Error in CAPA in Experiment 1}

The measure of CAPA used in Experiment 1 was an indirect measure, in that participants were not asked directly the extent to which they had considered the possibility of abandonment at the time of the initial project evaluation. Had such a direct question been asked, the additional mention of the possibility of project abandonment would have increased the construct accessibility of that possibility, as construct accessibility is generally increased by more frequent exposure to the construct (Etcheverry and Le 2005; Fazio and Williams 1986; Fazio et al. 1986). Thus, it was impossible to use such a direct measure of CAPA in Experiment 1, as the induced increase in construct accessibility would affect participants' tendency to later escalate commitment to the project under consideration.

TABLE 3

Experiment 1

Experimental Results: Recommendation to Continue Project (RCP) Considering Additional Calculations at Time 2

Panel A: ANOVA on RCPa

Source of Variation

CapBud

T2Calc

CapBud*T2Calc

Residual

\begin{tabular}{|c|c|}
\hline df & SS \\
\hline 1 & 5079.50 \\
\hline 1 & 7720.65 \\
\hline 1 & 815.33 \\
\hline 36 & 30199.08 \\
\hline
\end{tabular}

$\frac{F}{6.06}$
9.20
0.97

\begin{tabular}{r}
\multicolumn{1}{c}{ p } \\
\hline 0.02 \\
$<0.01$ \\
0.33
\end{tabular}

Panel B: Least-Squares Means: RCPh

\begin{tabular}{lc|c|} 
& \multicolumn{2}{c}{$\begin{array}{c}\text { Capital Budgeting } \\
\text { Method }\end{array}$} \\
\cline { 2 - 3 } Time 2 & $\begin{array}{c}\text { NPV } \\
\mathbf{n}=\mathbf{2 1}\end{array}$ & $\begin{array}{c}\text { Real Options } \\
\mathbf{n}=\mathbf{1 9}\end{array}$ \\
\hline Calculated & $\begin{array}{c}30.50 \\
\mathrm{n}=6\end{array}$ & $\begin{array}{c}15.75 \\
\mathrm{n}=6\end{array}$ \\
\cline { 2 - 3 } Did Not Calculate & $\begin{array}{c}70.70 \\
\mathrm{n}=15\end{array}$ & $\begin{array}{c}36.23 \\
\mathrm{n}=13\end{array}$ \\
\cline { 2 - 3 } & 50.60 & 25.99
\end{tabular}

\footnotetext{
"Likelihood of recommending project continuation measured on a 101-point scale with 0 labeled "Not at all likely," 50 labeled "Undecided," and 100 labeled "Extremely likely."

${ }^{b}$ RCP for those who performed additional calculations at Time 2 is not significantly different across capital budgeting conditions $(\mathrm{p}=0.42)$. RCP for those who did not perform additional calculations at Time 2 is significantly different across capital budgeting conditions $(\mathrm{p}<0.01)$.
} 
However, the use of an indirect measure increases the possibility of measurement error in capturing construct accessibility.

One possible reason that measurement error in CAPA was likely is that participants in the real options condition may not have felt the need to list abandonment among their scenarios since they had already considered such an eventuality when they first calculated the project value. In survey research, it has been found that sometimes respondents exclude information from their answer to a general question that has been addressed in a previous, more specific question in an attempt to provide only information that is "new" (Sudman et al. 1996, 123). If participants in this study followed such a judgment rule, then those in the real options condition who had already explored the possibility of abandonment in depth during their initial project calculation may have avoided listing that eventuality in the openended thought-listing task because the concept was not "new," while those in the net present value condition who had not explored the idea in depth would be more likely to mention it in the thought-listing task. The use of such a judgment rule could account for the anomalous findings in Experiment 1 with regard to $\mathrm{H} 2$.

One way to assess whether the results of the $\mathrm{H} 2$ test in Experiment 1 were due to measurement error in CAPA is to use an alternate measure of the construct. An examination of work done by participants at Time 2 indicates that some participants mentioned the dollar value of abandonment at that point, while others did not. Such mention is not a perfect measure of CAPA because it is made after the setback occurs, when participants are explicitly considering whether to abandon the project. In addition, participants are not required to answer any particular question about abandonment value at that point, so some participants with high CAPA may not have made mention of abandonment. However, such mention would be evidence that participants used the dollar value of abandonment in making their continuation decision, which would indicate that the information was salient to them. Thus, an additional test of $\mathrm{H} 2$ using participants' mention of the dollar value of abandonment as a measure of CAPA should indicate whether measurement error existed in the initial measure of CAPA. Results consistent with those using the initial measure of CAPA should increase our confidence that the initial measure captured CAPA well, while inconsistent results should decrease our confidence in the initial measure of CAPA.

A path analysis similar to that represented in Figure 1 was performed using this alternate measure. CAPA was captured using an indicator variable that equaled 1 if the participant mentioned the dollar value of abandonment, and equaled 0 if the participant did not mention the dollar value of abandonment. The results of this analysis are presented in Figure 2. The first-order coefficient for the direct effect, -0.427 , is statistically significant ( $p$ $=0.006$ ), while the path coefficient for the direct effect, -0.215 , is not statistically significant $(\mathrm{p}=0.088)$ in the presence of the mediating variable. The indirect effect on CapBud on RCP through CAPA, however, is -0.212 , which is statistically significant (Sobel test statistic $=-2.76, \mathrm{p}=0.006)$, as is each piece of that indirect effect. The effect of CapBud on CAPA is 0.347 ( $\mathrm{p}=0.028$ ), and the effect of CAPA on RCP is $-0.611(\mathrm{p}<0.001$ ).

These effects are completely consistent with the predictions of $\mathrm{H} 2$. There is a significant positive relationship between CapBud and CAPA, and a significant negative relationship between CAPA and RCP, as predicted by the hypothesis. The reduction from a significant first-order direct effect to an insignificant direct effect in the presence of the mediator is consistent with a total mediation of the main effect by the mediator variable (Baron and Kenny 1986). Thus, when mention of the dollar value of abandonment is used as a measure of CAPA, it completely accounts for the relationship between the capital budgeting method used and the tendency to escalate commitment to the project. Although this alternate measure of CAPA is not a perfect representation of the construct, the fact that a path analysis 
FIGURE 2

Experiment 1

Path Analysis with Alternate Measure of CAPA

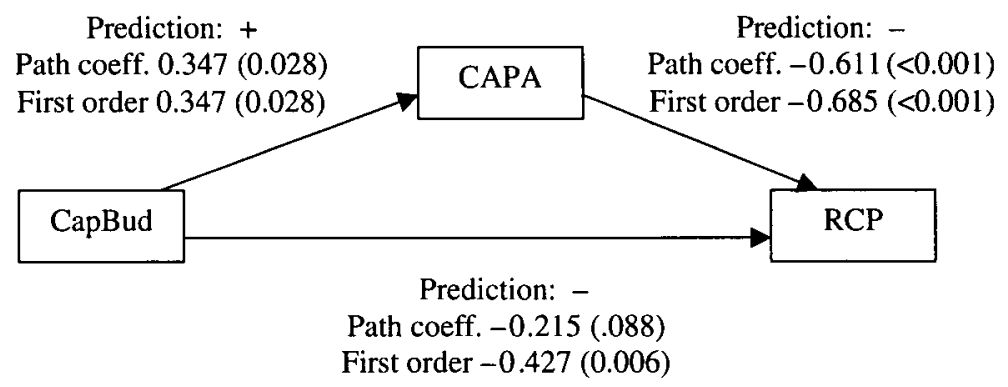

Path analytic model of CapBud (capital budgeting method), CAPA (construct accessibility of the possibility of abandoning the project early), and RCP (recommendation to continue the project). Path (standardized regression) coefficients are reported on paths with p-values in parentheses. First order correlations are also reported on paths with p-values in parentheses. CapBud is manipulated as either net present value (coded 0) or real options (coded 1) analysis. CAPA is measured as whether participants mentioned the dollar value of abandonment at Time 2 , coded 1 if they made such mention and 0 if they did not. RCP is measured as the likelihood of recommending project continuation at Time 2 measured on a 101-point scale with 0 labeled "Not at all likely," 50 labeled "Undecided," and 100 labeled "Extremely likely."

based on it yields opposite results from a path analysis based on the original measure of CAPA decreases our confidence in that original measure. This supports the contention that the original test of $\mathrm{H} 2$ failed due to measurement error rather than a deficiency in the underlying theory.

\section{Experiment 2}

To further address the possibility of inadequate measurement of CAPA in Experiment 1 , an additional experiment was conducted in which CAPA was measured in a different, more direct way. Such direct measurement of CAPA precludes a complete path analysis like that conducted in Experiment 1, since directly measuring CAPA would affect escalation of commitment. Thus, the new experiment only examines the first link in the path model, the relationship between capital budgeting method and CAPA. Evidence that this link is positive and significant will support the contention that the cognitive accessibility of the possibility of project abandonment mediates the relationship between the capital budgeting technique used and escalation of commitment.

The experiment was a simple $1 \times 2$ design in which the capital budgeting method used by participants was varied, and construct accessibility of the possibility of abandonment was measured. The method, analysis, and results of the study are described below.

\section{Participants}

Thirty-three Master of Business Administration students participated in the experiment. On average, these students were 30.11 years old, had 9.7 years of work experience, and 28.6 percent were female. This population was chosen because of its similarity to the population used in Experiment 1. Four participants were dropped because they did not complete the dependent variable of interest, leaving 29 participants in the study. 


\section{Design and Procedure}

The experiment was a simple two-cell design, in which capital budgeting was manipulated as a between-subjects variable. As in Experiment 1, participants were randomly assigned to a condition in which they used either net present value analysis alone or net present value analysis including the value of real options. The experimental scenario was identical to that in Experiment 1 until the point where participants indicated the likelihood that they would recommend funding the project and justified this choice with a short statement. After that point, participants were asked to indicate on a 101-point scale ranging from 0 (did not consider) to 100 (considered extensively) to what extent they considered nine different aspects of the project in deciding whether to recommend the project. These aspects included such factors as the project's cash flows, demand, marketability, and time span. The main factor of interest in this study, however, was "the possibility of abandoning the project before completion," which was used as the measure of CAPA, the dependent variable in the data analysis. After completing these questions, participants answered the same demographic and manipulation check questions as used in Experiment 1.

\section{Results}

\section{Manipulation Checks}

Participants were asked the same manipulation check questions as in Experiment 1. As in that experiment, participants were asked to what extent they agreed that the firm used net present value to evaluate its investment decisions on a scale of -5 to 5 . The mean response was 3.24 in the net present value condition and 2.37 in the real options condition. Both of these means are significantly different from 0 ( $p<0.01$ for both). The difference between conditions, however, is not significant $(\mathrm{p}=0.22)$. This is unsurprising considering that net present value is used in both conditions.

Participants were also asked to what extent they agreed that the firm used real options techniques to evaluate investment decisions on a scale of -5 to 5 . The mean response was 1.86 in the real options condition and -0.71 in the net present value condition. The mean in the net present value condition is not significantly different from $0(p=0.286)$, while the mean in the real options condition is significantly different from $0(p=0.011)$. The difference between conditions was significant $(p=0.010)$.

Of the remaining manipulation check questions, only two produced a statistically significant difference between the net present value and real options conditions. Participants in the net present value condition found the case easier to understand $(p<0.001)$ and less difficult $(\mathrm{p}=0.002)$ than participants in the real options condition. There were no significant differences in gender, age, or experience across capital budgeting conditions.

\section{Test of the Relationship between Capital Budgeting Method and Construct Accessibility}

The relationship between CapBud and CAPA is tested using a one-way ANOVA in which CapBud was the independent measure and CAPA was the dependent measure. Panel A of Table 4 presents the results of this ANOVA, and Panel B of Table 4 presents the mean CAPA for each group. As shown in Panel A, the effect in the model is highly significant $(\mathrm{F}=10.80, \mathrm{p}=0.003)$. The mean for CAPA in the real options condition (67.67) is significantly higher than that in the net present value condition (32.53). This is consistent with $\mathrm{H} 2$ in that it demonstrates that the capital budgeting method used by participants affects CAPA. Furthermore, an analysis of the participants' responses on each of the nine different aspects of the project (not shown) indicates that the possibility of abandoning the project early was the only aspect of the project for which there was a statistically significant 
TABLE 4

Experiment 2

Experimental Results: CAPA

Panel A: ANOVA on CAPA ${ }^{\mathrm{a}}$

\begin{tabular}{|c|c|c|c|c|c|}
\hline Source of Variation & $\underline{\text { df }}$ & SS & MS & $\mathbf{F}$ & $\mathbf{p}$ \\
\hline CAP & 1 & 8684.96 & 8684.96 & 10.80 & 0.0028 \\
\hline Residual & 27 & 21712.90 & 804.18 & & \\
\hline
\end{tabular}

Panel B: Cell Means: CAPA

\begin{tabular}{cc|c} 
& \multicolumn{2}{c}{$\begin{array}{c}\text { Capital Budgeting } \\
\text { Method }\end{array}$} \\
\cline { 2 - 3 } & \multicolumn{1}{c}{$\begin{array}{c}\text { NPV } \\
\mathbf{n}=\mathbf{1 7}\end{array}$} & $\begin{array}{c}\text { Real Options } \\
\mathbf{n}=\mathbf{1 2}\end{array}$ \\
\cline { 2 - 2 } CAPA & 32.53 & 67.67 \\
\cline { 2 - 3 } & &
\end{tabular}

\footnotetext{
${ }^{a}$ The extent to which participants considered the possibility of abandoning the project before completion when performing capital budgeting analysis, measured on a 101-point scale with 0 labeled "Did not consider," 50 labeled "Considered somewhat," and 100 labeled "Considered extensively."
}

difference between the two capital budgeting conditions, which helps to eliminate alternative explanations for the relationship between capital budgeting method and escalation of commitment.

\section{DISCUSSION}

This study demonstrates that decision makers who incorporate real options into their capital budgeting analyses exhibit less escalation of commitment to a failing course of action than users of net present value analysis. The proposal that the construct accessibility of the possibility of abandoning the project early mediates the relationship between real options usage and escalation of commitment is not supported in Experiment 1, but is supported when a more direct measure of such construct accessibility is used in Experiment 2. This section discusses these results and their implications, and acknowledges some limitations of the study.

\section{Discussion and Implications of Results Hypothesis 1}

The results of Experiment 1 are consistent with $\mathrm{H} 1$. Despite the fact that the capital budgeting technique used by participants did not affect the initial decision they made in accepting the project, the technique used did affect their decision to continue with the project after a setback. Participants who considered real options in their analysis were less likely than users of net present value alone to exhibit escalation of commitment to a failing course of action.

This result has implications for both research and practice. The finding adds to the escalation of commitment literature by offering a new avenue for reducing the bias. It adds to the real options literature by exploring to a limited extent the behavioral implications of the use of real options in capital budgeting analysis. This should suggest to real options researchers that the technique has effects beyond providing superior information; it also affects the behavior and decisions of managers even when its use should yield the same 
results as the use of net present value analysis alone. Hopefully, this will stimulate additional research into the behavioral effects of using real options in capital budgeting. In addition, this study has implications for firms that undertake capital budgeting projects, as it provides evidence that considering real options in the capital budgeting process can be superior to net present value techniques alone in reducing the tendency to escalate commitment to a failing course of action.

In addition, the finding that participants who recalculate the project's discounted cash flow value after a setback exhibit less escalation of commitment than those who do not provides another avenue for reducing escalation of commitment. It suggests that capital budgeting techniques should not be used solely in the initial evaluation stage of a project, but that they should be applied throughout a project as new information becomes available. Performing new analyses at later stages of a project can potentially reduce escalation of commitment regardless of the capital budgeting technique used.

\section{Hypothesis 2}

The results of Experiment 1 did not support H2. However, these results were likely the result of measurement error in capturing construct accessibility of the possibility of early abandonment. This deficient measurement was addressed by conducting a second experiment in which CAPA was measured more directly, and the link between capital budgeting technique and CAPA was tested. In Experiment 2, participants were asked to rate the extent to which they considered the possibility of early abandonment at the time they made the decision as to whether to undertake the project. This offers a measurement of CAPA that is much more in line with its actual definition and more representative of the mental state of participants than the measure used in Experiment 1. Because a more direct measure was used, however, escalation of commitment could not be assessed after measuring CAPA because of the likelihood that the measurement would interfere with subsequent decisions. Thus, only the first part of $\mathrm{H} 2$, that the capital budgeting method used by participants would affect CAPA, could be tested using the data from Experiment 2.

The results were consistent with $\mathrm{H} 2$; participants who used real options in the capital budgeting process had higher construct accessibility of the possibility of early project abandonment than participants who used net present value alone. Furthermore, there were no significant differences across capital budgeting conditions in the extent to which other factors were considered by participants - the future cash flows of the project, the probability that demand would be high versus low, the marketability of the product, the time span of the project, the impact of the project on performance evaluation, the incurrence of R\&D costs, project value, or other aspects of the project. The only significant difference among the project factors was in the extent to which the possibility of abandoning the project before completion was considered. This result helps to eliminate other potential reasons as to why escalation of commitment might differ between participants who use real options as part of the capital budgeting process and those who use net present value alone.

Although the results of Experiment 2 do not allow the construction of a complete path diagram as did Experiment 1, they lend support to the theory underlying the main results of Experiment 1, that the construct accessibility of the possibility of abandonment is higher for those using real options, and that this in turn affects the tendency of decision makers using real options to display less escalation of commitment to failing projects. Because Experiment 2 used a more direct measure of CAPA, this variable is subject to less measurement error than the measure used in Experiment 1, and is therefore more likely to capture the true nature of the construct. 


\section{Limitations}

It is possible that participants in the NPV condition who performed additional analysis at that time could have displayed escalation of commitment simply because they were following the instructions on how to perform an NPV analysis given in the experimental instrument. As those instructions pertained to performing an NPV analysis at the outset of the project when only one course of action was under consideration, they did not address a situation in which participants had to compare two potential courses of action, namely, continuing the failing project versus abandonment. Subjects performing such an analysis at Time 2 could have recommended to continue the project simply because the net present value was positive at that time, and the experimental instructions indicated that projects with a positive net present value should be approved.

However, as indicated in the analysis of work done at Time 2, participants in the NPV condition who performed additional analysis at that time displayed significantly lower escalation of commitment than those who did not perform additional analysis (see Table 3 ). Thus, it is highly unlikely that the results are driven by those participants in the NPV condition who decided to continue the project because their additional analysis at Time 2 yielded a positive net present value.

Another limitation of this study is that, as in any experimental study, the case is abstracted from reality, and considerably simpler than capital budgeting situations that would occur in an actual business setting. Although the psychological effect should generalize to actual business settings, it is unknown whether other factors might affect the results found here. In addition, the research participants are students, and although they should exhibit the same cognitive biases as working managers, it is unclear whether working managers actually would respond in the same way.

\section{Conclusion}

This study conducts an experiment to test whether the consideration of real options in capital budgeting affects escalation of commitment to a failing course of action. Results indicate that although the consideration of real options does not have a significant effect on the initial project acceptance decision, those participants who explicitly considered real options during the initial project evaluation were less likely to exhibit escalation of commitment to the project after the introduction of a setback than participants who used net present value analysis alone. In addition, results of a second experiment support the theory that the reduction in escalation of commitment among real options users is due to heightened construct accessibility of the possibility of early project abandonment at the time capital budgeting procedures are applied.

\section{APPENDIX \\ CASE AND SOLUTIONS \\ Case Given to Experimental Participants}

The aim of this project is to develop a device that includes a cell phone, electronic organizer, and 20GB MP3 player in one handheld unit. The product has already been developed by the $R \& D$ department, but the project will require an additional $\$ 100,000,000$ to build the production technology. This production technology can be sold at 55 percent of the value invested to date at any point during project development if the project is discontinued. The marketing department has reported that the project's expected cash flows will depend upon demand. There is a 60 percent chance that demand for the product will be high, with net cash flows of $\$ 60,000,000$ per year, and a 40 percent chance that demand 
will be low, with net cash flows of $\$ 10,000,000$ per year (we will learn which outcome will occur as soon as development is complete). Thus, the expected cash flows for the project are $\$ 40,000,000$ per year $(0.6 \times \$ 60,000,000+0.4 \times \$ 10,000,000)$. The project is expected to last 5 years. The company's required rate of return is 16 percent.

\section{Initial All-In-One Project Value Using Net Present Value and Real Options Analysis} Net Present Value

Find the present value of expected cash flows from the project and subtract the initial investment.

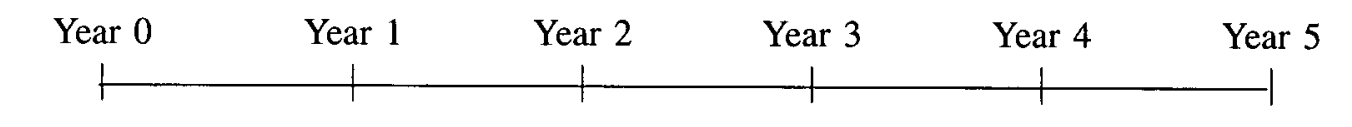

$\$(100,000,000) \quad \$ 40,000,000 \quad \$ 40,000,000 \quad \$ 40,000,000 \quad \$ 40,000,000 \quad \$ 40,000,000$

$\frac{\times 1}{\$(100,000,000)} \quad \$ 40,000,000 \times 3.274=\$ 130,960,000$

$\mathrm{NPV}=\$ 130,960,000-\$ 100,000,000=\$ 30,960,000$

\section{Real Options Value}

Find the present value of each possible scenario, choose the best outcome for each scenario, weight those outcomes by their probability of occurrence, and subtract the initial investment.

Scenario 1: The project earns $\$ 60,000,000$ per year, and the firm chooses to continue the project.

\begin{tabular}{|c|c|c|c|c|}
\hline Year 1 & $\begin{array}{c}\text { Year } 2 \\
+ \\
\end{array}$ & $\begin{array}{c}\text { Year } 3 \\
\quad+ \\
\end{array}$ & $\begin{array}{c}\text { Year } \\
+ \\
\end{array}$ & $\begin{array}{c}\text { Year } 5 \\
\end{array}$ \\
\hline$\$ 60,000,000$ & $\$ 60,000,000$ & $\$ 60,000,000$ & $\$ 60,000,000$ & $\$ 60,000,000$ \\
\hline
\end{tabular}

Scenario 2: The project earns $\$ 10,000,000$ per year, and the firm chooses to continue the project.

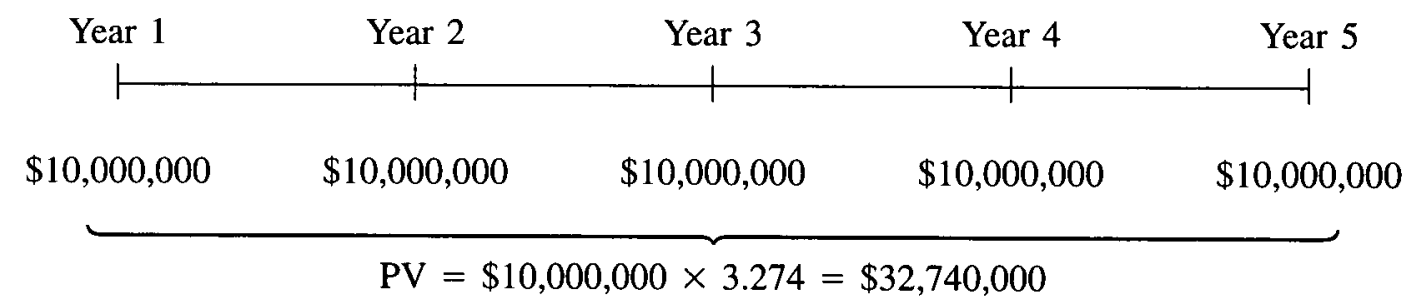


Scenario 3: The firm chooses to abandon the project.

The firm will earn $\$ 100,000,000 \times 55$ percent $=\$ 55,000,000$ from selling the production technology, so $\mathrm{PV}=\$ 55,000,000$.

Investment $\$ 100,000,000$

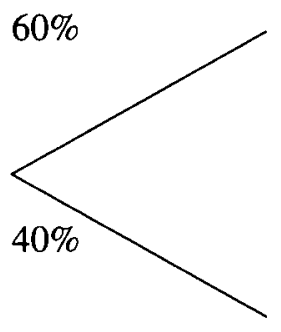

Annual cash flows $\$ 60,000,000$

Annual cash flows $\$ 10,000,000$

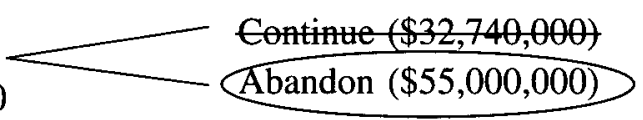

Proj. value $=(\$ 196,440,000 \times 60$ percent $)+(55,000,000 \times 40$ percent $)-\$ 100,000,000$ $=\$ 39,864,000$

Now the project value should be broken down into its discounted cash flow value and the value of the abandonment option:

Breakdown:

$$
\begin{aligned}
& \text { DCF Value } \\
& \text { Option Value } \\
& \text { Project Value }
\end{aligned}
$$

$\$ 30,960,000$ (NPV of expected cash flows)

$$
\frac{8,904,000 \text { (plug-in) }}{\$ 39,864,000 \text { (Real options value) }}
$$

\section{Value of All-In-One Project after the Setback Outlined in the President's Memo Net Present Value}

Find the present value of expected cash flows from the project and subtract the initial investment.

Year 0

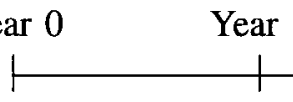

$\$(10,000,000)$

$\$ 10,000,000$

$\$ 10,000,000$

$\$ 10,000,000$

$\$ 10,000,000$

$\$ 10,000,000$

$\frac{\times 1}{\$(10,000,000)}$

$$
\$ 10,000,000 \times 3.274=\$ 32,740,000
$$

$\mathrm{NPV}=\$ 32,740,000-\$ 10,000,000=\$ 22,740,000$

Abandoning the project would bring in $\$ 90,000,000 \times 55$ percent $=\$ 49,500,000$

\section{Real Options Value}

The value using real options analysis is the same as that using net present value analysis, as there is no uncertainty to be resolved at this point.

\section{REFERENCES}

Adner, R., and D. A. Levinthal. 2004. What is not a real option: Considering boundaries for the application of real options to business strategy. Academy of Management Review 29 (January): 74-85. 
Amram, M., and N. Kulatilaka. 1999. Real Options: Managing Strategic Investment in an Uncertain World. Boston, MA: Harvard Business School Press.

Bargh, J. A., and R. D. Thein. 1985. Individual construct accessibility, person memory, and the recalljudgment link: The case of information overload. Journal of Personality and Social Psychology 49 (November): 1129-1146.

- and M. J. Ferguson. 2000. Beyond behaviorism: On the automaticity of higher mental processes. Psychological Bulletin 126 (November): 925-945.

Baron, R. M., and D. A. Kenny. 1986. The moderator-mediator variable distinction in social psychological research: Conceptual, strategic, and statistical considerations. Journal of Personality and Social Psychology 51: 1173-1182.

Beeler, J. D. 1988. Effects of counter-explanation on escalation of commitment: An experimental assessment of individual and collective decision. Advances in Accounting Behavioral Research 1: 85-99.

Bowman, E. H., and D. Hurry. 1993. Strategy through the option lens: An integrated view of resource investments and the incremental-choice process. Academy of Management Review 18 (October): 760-782.

Bragger, J. D., D. Bragger, D. A. Hantula, and J. Kirnan. 1998. Hysteresis and uncertainty: The effect of uncertainty on delays to exit decisions. Organizational Behavior and Human Decision Processes 74 (June): 229-253.

Busby, J. S., and C. G. C. Pitts. 1997. Real options in practice: An exploratory study of how finance officers deal with flexibility in capital appraisal. Management Accounting Research 8 (June): $169-186$.

Chartrand, T. L., and J. A. Bargh. 1996. Automatic activation of social information processing goals: Nonconscious priming reproduces effects of explicit conscious instructions. Journal of Personality and Social Psychology 71 (September): 464-478.

Cheng, M. M., A. K. Schulz, P. F. Luckett, and P. Booth. 2003. The effects of hurdle rates on the level of escalation of commitment in capital budgeting. Behavioral Research in Accounting 15: 63-85.

Chow, C. W., P. Harrison, T. Lindquist, and A. Wu. 1997. Escalating commitment to unprofitable projects: Replication and cross-cultural extension. Management Accounting Research 8 (September): $347-362$.

Conlon, E. J., and G. Wolf. 1980. The moderating effects of strategy, visibility, and involvement on allocation behavior-An extension of Staw's escalation paradigm. Organizational Behavior and Human Performance 26 (2): 172-192.

Copeland, T. E., and V. Antikarov. 2001. Real Options: A Practitioner's Guide. New York, NY: Texere.

Coy, P. 1999. Exploiting uncertainty: The "real-options" revolution in decision-making. BusinessWeek Online (June 7).

Dixit, A., and R. Pindyck. 1994. Investment Under Uncertainty. Princeton, NJ: Princeton University Press.

Drummond, H. 1996. Escalation in Decision-Making: The Tragedy of Taurus. New York, NY: Oxford University Press.

Etcheverry, P. E., and B. Le. 2005. Thinking about commitment: Accessibility of commitment and willingness to sacrifice. Personal Relationships 12 (March): 103-123.

Fazio, R. H., D. M. Sanbonmatsu, M. L. Powell, and F. R. Kardes. 1986. On the automatic activation of attitudes. Journal of Personality and Social Psychology 50 (February): 229-238.

- and C. J. Williams. 1986. Attitude accessibility as a moderator of the attitude-perception and attitude-behavior relations: An investigation of the 1984 presidential election. Journal of Personality and Social Psychology 51 (September): 505-514.

- and T. Towles-Schwen. 1999. The MODE model of attitude-behavior processes. In Dual Process Theories in Social Psychology, edited by S. Chaiken, and Y. Trope, 97-116. New York, NY: Guilford.

Fink, R. 2001. Reality check for real options: Applying Black-Scholes analysis to capital spending projects has one big flaw. CFO Magazine (September 1). 
Ghosh, D. 1997. De-escalation strategies: Some experimental evidence. Behavioral Research in Accounting 9: 88-112.

Goltz, S. M. 1993. Examining the joint roles of responsibility and reinforcement history in recommitment. Decision Sciences 24 (September/October): 977-994.

Graham, J. R., and C. R. Harvey. 2001. The theory and practice of corporate finance: Evidence from the field. Journal of Financial Economics 60 (May): 187-243.

Harrell, A., and P. Harrison. 1994. An incentive to shirk, privately held information, and managers' project evaluation decisions. Accounting, Organizations and Society 19 (October): 569-578.

Higgins, E., G. King, and G. Mavin. 1982. Individual construct accessibility and subjective impressions and recall. Journal of Personality and Social Psychology 43: 35-47.

1996. Knowledge activation: Accessibility, applicability and salience. In Social Psychology: Handbook of Basic Principles, edited by E. T. Higgins, and A. W. Kruglanski, 133-168. New York, NY: Guilford.

Howell, S., A. Stark, D. Newton, D. Paxson, M. Cavus, J. Pereira, and K. Patel. 2001. Real Options: Evaluating Corporate Investment Opportunities in a Dynamic World. London, U.K.: Prentice Hall.

Howell, S. D., and A. J. Jagle. 1997. Laboratory evidence on how managers intuitively value real growth options. Journal of Business Finance \& Accounting 24 (September): 915-935.

Jeffrey, C. 1992. Relation of judgment, personal involvement, and experience in the audit of bank loans. The Accounting Review 67 (October): 802-819.

Kadous, K., and L. M. Sedor. 2004. The efficacy of third-party consultation in preventing managerial escalation of commitment: The role of mental representations. Contemporary Accounting Research 21 (Spring): 55-82.

Kanodia, C., R. Bushman, and J. Dickhaut. 1989. Escalation errors and the sunk cost effect: An explanation based on reputation and information asymmetries. Journal of Accounting Research 27 (Spring): 59-77.

Keil, M., R. Mixon, T. Saarinen, and V. Tuuainen. 1994. Understanding ruanway information technology projects: Results from an international research program based on escalation theory. Journal of Management Information Systems 11 (Winter): 65-85.

- and J. Flatto. 1999. Information systems project escalation: A reinterpretation based on options theory. Accounting, Management and Information Technologies 9 (2): 115-139.

Kogut, B., and N. Kulatilaka. 1994. Options thinking and platform investments: Investing in opportunity. California Management Review 36 (Winter): 52-71.

Lander, D. M., and G. E. Pinches. 1998. Challenges to the practical implementation of modeling and valuing real options. Quarterly Review of Economics 38 (Special Issue): 537-567.

McGrath, R. G. 1999. Falling forward: Real options reasoning and entrepreneurial failure. Academy of Management Review 24 (January): 13-20.

Miller, D., C. Droge, and S. Vickery. 1997. Celebrating the "essential": The impact of performance on the functional favoritism of CEOs in two contexts. Journal of Management 23 (2): 147168.

Miller, K. D., and Z. Shapira. 2004. An empirical test of heuristics and biases affecting real option valuation. Strategic Management Journal 25 (March): 269-284.

Myers, S. C. 1977. Determinants of corporate borrowing. Journal of Financial Economics 5 (November): 147-176.

Newton, D. P., D. A. Paxson, and M. Widdicks. 2004. Real R\&D options. International Journal of Management Reviews 5-6 (June): 113-130.

Posavac, S. S., D. M. Sanbonmatsu, and R. H. Fazio. 1997. Considering the best choice: Effects of the salience and accessibility of alternatives on attitude-decision consistency. Journal of Personality and Social Psychology 72 (February): 253-261.

Ratneshwar, S., L. Warlop, D. G. Mick, and G. Seeger. 1997. Benefit salience and consumers' selective attention to product features. International Journal of Research in Marketing 14: 245-259.

Ross, S. 1995. Uses, abuses, and alternatives to the net-present-value rule. Financial Management 24 (Autumn): 96-102. 
Rutledge, R. W., and K. E. Karim. 1999. The influence of self interest and ethical considerations on managers' evaluation judgments. Accounting, Organizations and Society 24 (February): 173184.

Schmidt, J. B., and R. J. Calantone. 2002. Escalation of commitment during new product development. Journal of the Academy of Marketing Science 30 (Spring): 103-118.

Schoorman, F. D., and P. J. Holahan. 1996. Psychological antecedents of escalation behavior: Effects of choice, responsibility, and decision consequences. The Journal of Applied Psychology 81 (December): 786-794.

Schulz, A. K., and M. M. Cheng. 2002. Persistence in capital budgeting reinvestment decisionsPersonal responsibility antecedent and information asymmetry moderator: A note. Accounting and Finance 42 (March): 73-86.

Staw, B. M. 1976. Knee-deep in the big muddy: A study of escalating commitment to a chosen course of action. Organizational Behavior and Human Performance 16 (June): 27-44.

, and H. Hoang. 1995. Sunk costs in the NBA: Why draft order affects playing time and survival in professional basketball. Administrative Science Quarterly 40 (September): 474-494. - 1997. The escalation of commitment: An update and appraisal. In Organizational Decision Making, edited by Z., Shapira, 191-215. Cambridge, U.K.: Cambridge University Press.

Sudman, S., N. M. Bradburn, and N. Schwarz. 1996. Thinking about Answers: The Application of Cognitive Processes To Survey Methodology. San Francisco, CA: Jossey-Bass.

Teach, E. 2003. Will real options take root? Why companies have been slow to adopt the valuation technique. CFO Magazine (July 1).

Tiwana, A., M. Keil, and R. G. Fichman. 2006. Information systems project continuation in escalation situations: A real options model. Decision Sciences 37 (3): 357-391.

- J. Wang, M. Keil, and P. Ahluwalia. 2007. The bounded rationality bias in managerial valuation of real options: Theory and evidence from IT projects. Decision Sciences 38 (1): 157181.

Trigeorgis, L. 1997. Real Options: Managerial Flexibility and Strategy in Resource Allocation. Cambridge, MA: The MIT Press.

Yavas, A., and C. F. Sirmans. 2005. Real options: Experimental evidence. The Journal of Real Estate Finance and Economics 31 (1): 27-52.

Zardhooki, A. 2004. Do real options lead to escalation of commitment? Academy of Management Review 29 (January): 111-119. 
Copyright of Accounting Review is the property of American Accounting Association and its content may not be copied or emailed to multiple sites or posted to a listserv without the copyright holder's express written permission. However, users may print, download, or email articles for individual use. 